\title{
Changing the culture of neurodisability through language and sensitivity of providers: Creating a safe place for LGBTQIA+ people
}

\author{
Alexander Moreno ${ }^{\mathrm{a}, \mathrm{b}, *}$, Ari Laoch ${ }^{\mathrm{c}}$ and Nathan D. Zasler ${ }^{\mathrm{d}}$ \\ ${ }^{a}$ Faculty of Human Sciences, Department of Sexology, Université du Québec à Montréal (UQÀM), Canada \\ ${ }^{\mathrm{b}}$ Center for Interdisciplinary Research in Rehabilitation of Greater Montreal, Canada \\ ${ }^{\mathrm{c}}$ Virginia Commonwealth University, Richmond, VA, USA \\ ${ }^{\mathrm{d}}$ Concussion Care Centre of Virginia, Ltd. and Tree of Life Services, Inc., Henrico, VA, USA
}

\begin{abstract}
.
BACKGROUND: There is an increasing interest in sexual and gender diversity in neurorehabilitation. Healthcare professionals wanting to improve their practice know the importance of understanding the needs and expectations of specific communities.

OBJECTIVE: To critically review the literature about neurological disorders in people who identify as lesbian, gay, bisexual, transgender, queer, intersex, asexual, and people with other sexual orientations and forms of gender expression (LGBTQIA+). METHODS: Systematic search in electronic databases (CINAHL, EMBASE, Medline, PsycINFO, Scopus, and Web of Science) and identification of relevant studies.

RESULTS: Quantitative and qualitative findings are summarized and reported by neurological disorders: a) neurodisability/epilepsy (17.7\%), b) intellectual disability/autism spectrum disorders (19.6\%), c) dementia/HIV-related dementia (39.2\%), d) spinal cord injury (7.8\%), and e) traumatic brain injury/stroke (15.7\%).

CONCLUSIONS: LGBTQIA+ people with neurodisabilities and their partners/families of choice can conceal their sexual orientation or gender identity for fear of diminished quality of care. Their invisibility translates into health disparities, lack of policies and services that meet their unique needs. Dementia is the most common neurodisability documented in LGBTQIA+ people. We provide recommendations to increase LGBTQIA+ cultural competency for clinical practice, research, and policy to help different stakeholders to promote a positive change in the culture of neurodisability.
\end{abstract}

Keywords: Neurosexuality, LGBTQIA+, LGBT, neurodisability, sexual diversity, gender identity, sexual orientation

\section{Introduction}

As healthcare professionals working with persons with neurodisabilities, it is paramount for us

\footnotetext{
*Address for correspondence: Alexander Moreno, Ph.D., Faculté des sciences humaines, Département de sexologie, Université du Québec à Montréal (UQÀM), C.P. 8888, Succ. CentreVille, Montréal, QC, H3C-3P8, Canada. E-mail: moreno.jhon_ alexander@uqam.ca.
}

to facilitate inclusion and promote understanding of all individuals regardless of their sexual orientation and gender identity. There are many challenges to provision of healthcare services in neurorehabilitation that serve as potential obstacles to optimal individual care; yet, one that is rarely discussed in the context of neurodisability management is how to facilitate the care of lesbian, gay, bisexual, transgender, queer, intersex, asexual, and people with other 
sexual orientations and forms of gender expression (LGBTQIA+) (Sandel, Delmonico, \& Kotch, 2013; Yarns, Abrams, Meeks, \& Sewell, 2016). The diagnosis of a "neurodisability" brings with it potential stigma and marginalization inherent in the use of the term disability. Neurodisability, as a diagnosis, is broad encompassing a vast spectrum of impairments in terms of nature as well as severity. Neurodisability describes a group of congenital or acquired longterm conditions that are attributed to impairment of the brain and/or neuromuscular system and create functional limitations (e.g., with movement, cognition, hearing and vision, communication, emotion, and behavior); a specific diagnosis may not be identified and conditions may vary over time, occur alone or in combination, and include a broad range of severity and complexity (Morris, Janssens, Tomlinson, Williams, \& Logan, 2013). The "functional limitation" identifier within the definition points to a reliance upon paid professionals, guardians, and significant others to complete tasks deemed relevant to one's function. It is within this vein that sexuality may be impaired and that misconceptions about sexual orientation and gender identity mediate treatment outcomes. Poor knowledge, bias, and/or prejudice contribute to poor treatment and physical health disparities (Dorsen \& Van Devanter, 2016; Lapinski, Sexton, \& Baker, 2014).

Dorsen and Devanter (2016) noted that "LGBT persons experience multiple health inequities and that stigma and marginalization, including that from healthcare providers, play a major role in perpetuating them" (p. 3718). Healthcare inequalities may result from providers non-equanimitous care to those they deem to be "less than" or "unworthy" of their care. Lapinski et al., (2014) reported poorer healthcare to LGBTQIA+ people and, in some cases, refusal to provide care to persons seeking medical services based upon sexuality or gender identity. A research concern has been posited relative to the potential that LGBTQIA+ people withhold reporting sub-optimal healthcare for fear of reprisal because of their sexuality or gender identity, and/or the fact of being "in the closet". Muson and Cook (2016) convey the challenges of lesbian and bisexual women having to "come out" repeatedly to medical providers as a result of their clinicians' assumptions of heterosexuality. Lesbian and bisexual women report that a fear of being judged unfairly, based on assumptions of heterosexuality, create discomfort to further discuss medical concerns (Munson \& Cook, 2016). The lack of attention to the sexual health of an LGBTQIA+ person contributes to decreased attendance to medical appointments and the decreased congruence of relationship between provider and client. As such, LGBTQIA+ people having a neurodisability may remain invisible despite having intertwined relationships with providers, be they personal care professionals, medical providers, or educators.

Healthcare provider barriers to addressing this community include such issues as: a) individual fears regarding potential misperceptions about their lives and practices; b) discrimination by healthcare practitioners; c) moral condemnation as well as outright rejection. All too often, traditional healthcare tends to presume that individuals accessing healthcare are heterosexual until proven otherwise. Such assumptions do not set a solid foundation for development of productive healthcare professional-individual or in more general terms, clinician-individual relationships. A person's sexual orientation and gender identity are certainly crucial pieces of historical information that are important to establish in any healthcare relationship; yet, how comfortable are most healthcare practitioners in soliciting this type of information (Mayer et al., 2008). Unfortunately, many clinicians lack sensitivity towards people with non-heterosexual orientations and non-binary gender identities in part, due to lack of adequate training and sometimes in part, due to prejudices as well as religious, moral, cultural and/or other biases (Moorley, Neville, \& Johnson, 2016).

Often times LGBTQIA+ issues are even more significant in the context of an acquired or congenital neurodisability secondary to pre-existing societal views and prejudices are further compounded by compromised mobility, range of motion and/or abilities to convey or understand information, express their gender/sexuality and/or develop and maintain intimate relationships. Clinicians must understand how non-hegemonic sexual orientations and gender identities may create unique challenges and needs for LGBTQIA+ people and their partners, as relevant, including dealing with issues such as sexual minority stress, alienation, and adjustment disorder issues, among other phenomena (Meyer, 2014). There has also been research suggesting that the social constructions of illness in same-sex marriages are different from those of heterosexual marriages, with samesex couples experiencing less stress around illness and care work, which also needs to be appreciated in the context of working with LGBTQIA+ people (Umberson, Thomeer, Reczek, \& Donnelly, 2016). Concerns regarding confidentiality may also limit 
disclosure by the LGBTQIA+ person and/or their partner particularly in interdisciplinary, group settings (Sandel et al., 2013). Other barriers that are related to the aforementioned include lack of specialized and knowledgeable screening, education and treatment for reproductive health, sexuality and sexual performance related issues. Additionally, there may be alterations in sexual function associated with the neurodisability, such as have been described in association with stroke, traumatic brain injury and epilepsy, that must also be appreciated by treating clinicians. That being said, one must also acknowledge that there is a dearth of quality evidence-based literature examining how these issues should be addressed in the LGBTQIA+ population and whether approaches should be parallel to or diverse from those used in heterosexual clients.

The rehabilitation of people with neurodisabilities must also include assessment and treatment of issues related to sexuality, as well as sexual function in the context of the particularities of their sexual orientation and gender identity (Sandel et al., 2013). Clinicians must appreciate and understand the spectrum of sexual diversity that exists in the context of general client assessment as well as treatment, and this is no different for persons with congenital or acquired neurodisabilities. The best way to collect such information is understanding how to take a nonjudgmental, thorough sexual history as described by Zasler \& Martelli (2011). Sexual healthcare specifically, may be further complicated in neurodisability by associated impairments of bowel and bladder function, spasticity, contracture, speech/communication and oromotor impairments, cognitive challenges, behavior dysregulation, as well as compromised social skills and pragmatics. Knowledge of how these impairments may impede sexual expression is paramount, as is a skill base that allows the treating clinician to provide interventions to overcome and/or compensate for them as relevant to the LGBTQIA+ population (Zasler \& Martelli, 2011). Healthcare providers often times incorrectly make the assumption that people with disabilities are not "sexual" or sexually active, which is often far from true (Esmail, Darry, Walter, \& Knupp, 2010). On the contrary, a study revealed that women with physical disabilities have as much sexual desire as non-disabled women (Nosek, Howland, Rintala, Young, \& Chanpong, 2001). Commonly held beliefs amongst health professionals regarding sexuality, gender, and disability must be extinguished through education including dispelling views that individuals with neurodisabil- itites are asexual, uninterested in or incapable of sexual relationships, and/or unattractive to others. We, as professionals working with individuals with disabilities, must remove barriers that are often faced by these individuals with regards to sexual expression, as long as that expression does not put them at risk for exploitation or assault (Casteel, Martin, Smith, Gurka, \& Kupper, 2008).

Given the dearth of information on how sexual diversity intersects with neurodisability, we have an obligation not only to discuss these issues but also to find ways to facilitate the healthcare of those LGBTQIA+ people with neurodisabilities to whom we provide care (as well as their families, partners, and/or significant others). The aim of this study is to critically review the literature about neurological disorders in people who identify as LGBTQIA+.

\section{Methods}

\subsection{Procedure}

To capture the literature about neurological disorders in LGBTQIA+ people, we searched published articles with the following inclusion criteria: a) publications from all health professions, b) describing different neurological disorders, c) both developmental and acquired brain injuries, d) restricted to LGBTQIA+ people, e) regardless of year of publication, f) qualitative and quantitative studies, g) reports, book chapters, case studies, letters to the editor, and short notes published in peer-reviewed journals, $h$ ) available in English language. We excluded: a) conference abstracts, b) articles published in languages other than English, c) studies addressing heterosexual or gender conforming populations, d) reports of conversion therapy (e.g. "reparative" or "ex/gay" therapy), e) grey literature defined as any documentary material that is non-commercially published such as technical reports, thesis' repositories, materials produced by associations and the industry, government documents, and working papers (Farace \& Schöpfel, 2010).

The following databases were searched from 1946 to present: CINAHL, EMBASE, Medline, PsycINFO, Scopus, and Web of Science. In the same search, we included the keywords for LGBTQIA+ (e.g., LGBT, homosexuality, lesbian, gay, intersex, bisexuality, transgender, transsexualism, transvestism, hermaphroditism, androgyny, sexual diversity, and sexual expression) and different 
neurological disorders (e.g., traumatic brain injury, spinal cord injury, brain injury, epilepsy, multiple sclerosis, amyotrophic lateral sclerosis, stroke, and dementia). Using a reference management software (EndNote X7) (Moon \& Park, 2014), the results were merged and the duplicates removed before the initial screening. Additional records were identified using hand-searches (e.g., reference list of the articles retained). Later, a data extraction form was developed by the research team to screen the titles and abstracts based on the inclusion/exclusion criteria. The authors conducted the selection of abstracts based on the inclusion criteria. Different discussions were held regarding the search strategy and the study selection when there was uncertainty about the retention of one study (Higgins \& Green, 2011). Finally, all eligible studies and those classified as unclear (i.e., requiring further information to make a final decision regarding their retention) were reviewed as full-text articles for compliance with eligibility criteria. Disagreements were resolved by consensus. Figure 1 presents the PRISMA flow diagram depicting the different phases of the review.

\section{Results}

The systematic search led to the identification of a total of 377 entries, classified by database as follows: a) CINAHL $(n=91)$, b) EMBASE $(n=18)$, c) Medline $(n=79)$, d) PsycINFO $(n=40)$, e) Scopus $(n=85)$, and f) Web of Science $(n=64)$. We excluded 260 titles and abstracts for the following reasons: a) two $(0.8 \%)$ were not available in English, b) two $(0.8 \%)$ were conference abstracts, c) $45(17.3 \%)$ were not LGBTQIA+-related, d) 42 (16.1\%) addressed LGBTQIA+-related issues but not neurodisability, and e) $169(65 \%)$ were studies that recruited LGBTQIA+ participants mainly for HIV/AIDS research but did not address sexual orientation or gender identity as a variable of analysis, as well as a few reports of conversion therapies. Following the selection of titles and abstracts, 51 studies were included in the review. A synthesis of the studies retained is presented in five different sections: a) neurodisability/epilepsy, b) intellectual disability/autism spectrum disorders, c) dementia/HIV-related dementia, d) spinal cord injury, and e) traumatic brain injury/stroke. The results are presented in a quantitative synthesis and a summary of the main findings by neurological disorder. To integrate the results, two neurological disorders are presented under the same heading when they share similar characteristics or when the evidence involving LGBTQIA+ people overlaps for the two neurological disorders.

\section{Neurodisability/Epilepsy}

Nine references were retained following the screening of titles and abstracts. Eight $(15.7 \%)$ correspond to neurodisability (Banks, 2003; Barrett, 1990; "Clinical digest," 2005; Colin, 2015; Rosendale \& Andrew Josephson, 2015; Willis, Ward, \& Fish, 2011; Witten, 2014; Yarns et al., 2016) and one (2\%) to epilepsy (Hunter, 1967). Following the full-text assessment, we excluded one article that was not specific to LGBTQIA+ people with neurodisabilities describing general resources to address the needs of gay and lesbian deaf persons, counseling with homosexual children, and sexuality after spinal cord injuries and stroke for heterosexual individuals (Barrett, 1990). Of the nine references, eight identified a need for addressing bias towards persons of diverse sexuality and gender.

Banks (2003) affirms that the needs of lesbian and bisexual women with acquired disabilities are often ignored or ridiculed to the point that some of them have their support systems disrupted as a "punishment" for their sexual orientations. The same author was unable to locate literature about transgender people with disabilities (Banks, 2003). As such, research about different neurodisabilities reveals a reality of health disparities and inequalities. The needs and concerns of older gay and lesbian people have been ignored from the clinical, research, and policy perspectives ("Clinical digest," 2005). Exploring and challenging heterosexist and homophobic attitudes, as well as educating and training providers can result in equal medical, psychological, legal, and ethical treatment regardless of sexual orientation and gender identity. A study with 10 LGBT family caregivers revealed that information about sexual orientation and gender identity is not being recorded ("an absent presence") because there are not safe spaces to facilitate appropriate communication and information sharing with healthcare providers (Willis et al., 2011). The authors suggest that invisibility of their sexuality reinforces heterosexuality as a social marker and fails to evidence experiences of discrimination. As a consequence, it is still unclear if neurological diseases are in fact more prevalent in LGBTQIA+ people given the disparities in risk factors for this community 


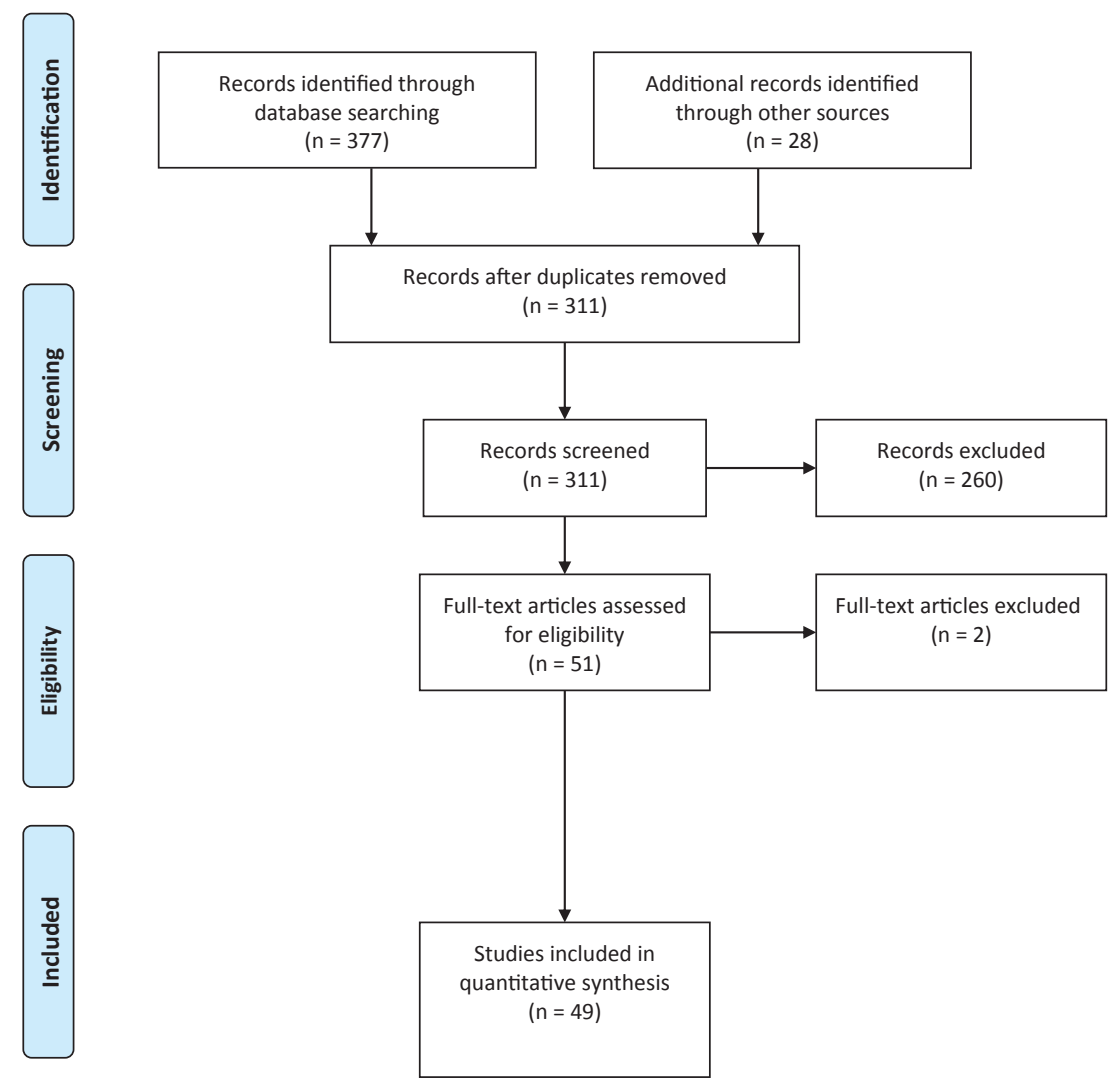

Fig. 1. PRISMA flow diagram for neurodisability and LGBTQIA+ literature.

(Rosendale \& Andrew Josephson, 2015). In broader terms, "the fundamental tenet of all medical care is the acceptance of patients as they are, for who they are, with respect and without prejudice" (Colin, 2015) (p. 1209).

However, LGBTQIA+ people are more likely to experience physical and mental health disparities than their counterparts, are less likely to seek medical services, and have "more difficulty obtaining appropriate health care" (Yarns et al., 2016). A hidden consideration may also result from LGBTQIA+ people not medically reporting due to fear of "reprisal" because of their sexuality or gender identity. Some transgender persons would prefer opting to die at their own hand through "euthanasia" rather than dying at the hand of potentially abusive caretakers (Witten, 2014).

Although there is an absence of any substantive epilepsy medical literature that assesses issues germane to the LGBTQIA+ population, there are likely a number of concerns that are relevant including how concurrent treatment with hormone therapy in persons undergoing sex reassignment may interfere with anti-epileptic drug (AED) therapy and how one should accommodate that from a treatment and AED dosing standpoint. There is interesting literature that suggests that uncontrolled epilepsy and damage to different brain regions may alter sexual behavior (Hunter, 1967). We do not know how epilepsy, particularly when chronic and not well controlled, may alter brain morphology and potentially sexuality and sexual function in LGBTQIA+ people. It is well known from the general epilepsy literature that epilepsy is associated with hyposexuality and this of course must be considered in all individuals regardless of sexual orientation or gender identity. What role epilepsy may have in altering sexual orientation or gender identity remains poorly studied; although, there is at least one report in the literature of a transgender individual whose gender identity and personality were altered following an episode of status epilepticus (Parkinson, 2015). Ictal sexual behaviors in temporal lobe epilepsy may be misinterpreted as atypical sexual behaviors and must be differentiated from same. On occasion, surgical resection of epileptic foci associated with temporal lobe epilepsy may 
result in hypersexual behavior. A number of other sexual behaviors have been reported in association with temporal lobe dysfunction/epilepsy more commonly associated with non-dominant lesions (Baird, Wilson, Bladin, Saling, \& Reutens, 2007).

\section{Intellectual Disability/Autism Spectrum Disorders}

Ten references were selected following the screening of titles and abstracts of neurodisability and LGBTQIA+ concerns. Five (9.8\%) correspond to intellectual disability (ID) (Marshall, 2012; McCann, Lee, \& Brown, 2016; McClelland et al., 2012; Tallentire et al., 2016; Thomas \& DeAlwis, 1995) and five (9.8\%) to autism spectrum disorders (ASD) (Bashe, 2012; El-Ghoroury, 2012; Ingudomnukul, Baron-Cohen, Wheelwright, \& Knickmeyer, 2007; Newsom, Weitlauf, Taylor, \& Warren, 2012; Parsi \& Elster, 2012). Persons diagnosed with ID and ASD are more likely to use medical and mental health services and tend to have decreased socialization as compared to their age-matched peers (McCann et al., 2016; McClelland et al., 2012). However, LGBTQIA+ people having a diagnosis of ID or ASD may face being infantilized resulting in a lack of recognition of any sexuality. As persons age and develop academic or occupational interests, the need for leisure activity and social interaction becomes omnipresent. Safe spaces to meet like-minded individuals that express a similar culture and perspectives can be invaluable to validating a personal existence, to making friends, or finding a partner.

Thomas and DeAlwis (1995) found an association between freedom of expression and a decrease in aggressive behavioral presentation in a case report of an individual with a learning disability who reduced his aggressive behavior when he was able to express his sexuality after moving from the hospital to the community. In addition, studies show that poor knowledge of sexuality and gender identity issues leaves a person with ID without the necessary assistance and guidance to make informed choices about safer sex practices, and their right to include pleasure, romance, companionship, and community (McCann et al., 2016; McClelland et al., 2012; Saxe \& Flanagan, 2013). McClellan et al. (2012) reported that a lack of support and education to providers resulted in fewer safe spaces in a sample of 10 LGBT young adults with ID receiving services. Concepts of a "safe space" translate into social places to meet and gather with other like-persons for the development of friendships and romantic involvement outside of a parent's or community home. McClellan et al. (2012) also referred to "finding a safe space" as places for young LGBT persons with ID to engage in consensual sexual activity. Participants interviewed reported to be engaging in sexual activities in outdoor spaces, which they regarded as less safe and less comfortable, and where they would be least likely to use a condom. LGBTQIA+ people may face arrest, prosecution, and further stigma engaging in sexual activity outdoors, as well as, assault, and violence. As noted in the study, LGBT young adults with ID engaging in sexual activity outdoors are less likely to employ safer sex practices. One 19-year-old gay participant with ID affirmed that condoms are present in his home "next to the bed" and that he is more likely to use them at home. The participant goes on to note that: "when you are at your partner's house and you know that person well, and you trust that person and you love that person, then the relationship is good" (McClelland et al., 2012) (p. 815). This statement can be read as a person explaining their understanding of "love". The sentiment is that providers who lack information and knowledge lead to people making dangerous decisions.

Tallentire et al. (2016) conducted a study using a participatory approach to describe the experiences of 18 individuals with ID who attended an LGBT support group in a secure ID service. The results indicate that attending to an LGBT group helped individuals with ID to take pride of their sexual identity, develop a sense of purpose, and to improve their self-esteem and psychological wellbeing. The authors conclude that there is a need to explore and change attitudes of staff and clients to develop a culture "that respects diverse sexualities" (p. 9).

In a review of 14 studies regarding the experiences and support needs of individuals with ID who identify as LGBT, the authors conclude that there are several opportunities to better support their health and social care needs (McCann et al., 2016): a) education for staff to provide information in an accessible format about sexual identity, relationships, and practices for LGBT individuals with ID; b) practitioners need to acknowledge the possibility that an individual with ID may also be LGBT, and be aware and challenge the paternalistic, heteronormative and negative attitudes prevalent within some organizations; c) from a human rights perspective, there is a need to discuss concerns of vulnerability, capacity, consent, abuse, and exploitation of LGBT individuals with ID; and 
d) from a research perspective, there is a need to develop the evidence-base in this area considering the context of a change from institutional to communitybased models of care in individuals with ID.

Parsi and Elster (2012) identify the need for the parents and community members to support and provide opportunities for the positive growth and maturation of persons with ASD. Perhaps a hidden obstacle in treatment options for persons with ASD is the historical attempt to conform the person into a "normed" societal standard or "paternalistic" behavior of providers contributing to an infantilized approach further limiting the dialogue of a diverse sexuality or gender (Newsom et al., 2012). Persons with diagnosis of ID or ASD have increased social contact with paid professionals, thus lessening the influence of age-appropriate peer contact that can shape social norms, behaviors, and societal expectations. A study showed that compared to neurotypical women (1.6\%), women with ASD reported bisexual $(13.2 \%)$ or reduced sexual interests (17\%) (Ingudomnukul et al., 2007). The authors interpret the findings as supportive of the androgen theory of ASD with heightened testosterone levels and they acknowledge the possibility that these women may be disinterested in sex because of the great social challenges inherent to a romantic relationship. However, there is a report of a parent who describes a successful relationship of her female-to-male transgender son with autism (ElGhoroury, 2012) with another man, which illustrates the complexity of intersections between neurodisability, sexual orientation and gender identity. The mother of this transgender individual with ASD illustrates the personal struggle when integrating neurodisability and gender identity: "my personal thinking was clouded by my own unacknowledged transphobia, homophobia, ageism, and ableism" (Parsi \& Elster, 2012) (p. 209). As such, individuals with ASD need evidence-based training in sexuality and relationships throughout their lives by practitioners who challenge their views as asexual, child-like, hypersexual or deviant (Bashe, 2012).

Transgender issues in the context of ASD have shown new developments that were not captured when the search for the current study was conducted, including two case studies of high-functioning individuals diagnosed with ASD and gender dysphoria (Jacobs, Rachlin, Erickson-Schroth, \& Janssen, 2014), a report documenting autistic features in young people with gender dysphoria (Skagerberg, Di Ceglie, \& Carmichael, 2015), two reviews about co-occurring gender dysphoria and ASD (up to 20\%)
(Glidden, Bouman, Jones, \& Arcelus, 2016; Van Der Miesen, Hurley, \& De Vries, 2016), and initial clinical guidelines for co-occurring ASD and gender dysphoria or incongruence in adolescents (Strang et al., 2016).

\section{Dementia/HIV-Related Dementia}

A total of 20 references were retained following the screening of titles and abstracts. Of those, 17 $(33.3 \%)$ correspond to dementia and $3(5.9 \%)$ to HIV-related dementia. Following the full-text article assessment, we excluded one paper because it was not LGBTQIA+-related (Ward, Vass, Aggarwal, Garfield, \& Cybyk, 2005). Among the 17 papers included under "dementia and LGBTQIA+", six were short pieces addressing different topics, as follows: a) a recruitment advertisement for a study aiming to explore dementia from an exclusive homosexual perspective (Price, 2003), b) the development of a gay and lesbian caregiver network offering financial and legal telephone support in the UK (Moriarty, 2003), c) the invisibility of older lesbians and their experience of discrimination in healthcare systems leading them to "pass" as heterosexuals (Archibald, 2006), d) the lack of recognition of the existence of gay people living in care homes and their particular needs (Knocker, 2006), e) a gay man's experience as a family caregiver doing his "coming out" twice when his father diagnosed with dementia forgot about his sexual orientation (Bel Bruno, 2009) and, f) a brief note to denounce the lack of a plan for LGBT issues in the national strategy for dementia of the UK, where there is an estimated 1.2 million older LGBT population ("In brief," 2016).

Two of the 17 articles about dementia and LGBTQIA+ people were theoretical works. A first piece illustrates the need to validate the experience of gay family caregivers in the development of a lesbian and gay caregiver network in the UK that has been successfully functioning for two years (Newman, 2005). In addition, a narrative approach aiming to describe the experience of late-life dementia for members of the LGBT community concluded that LGBT people with dementia go through a loss of identity; that is, institutionalized cultural incompetency leads to a double invisibility of LGBT people because of the multiple oppressions coming from the intersection of sexuality and stigma (i.e., LGBT identity), sickness (i.e., dementia), and advancing years (i.e., ageism) (McGovern, 2014). 
Eight of the 17 papers included case reports (Anetzberger, 2004; Ward, 2000), an article describing the development of a telephone support group for gay and lesbian people living with dementia (Moore, 2002), and five qualitative studies describing the experience of LGBT people living with dementia and their family caregivers (Barrett, Crameri, Lambourne, Latham, \& Whyte, 2015; Price, 2008, 2010, 2011, 2012).

In a case report of elder abuse situations, there is a story of an older lesbian woman who lost her life partner following a surgery and who struggles with cognitive impairment while living alone without any support of family or friends (Anetzberger, 2004). Another case report features the story of a gay man with early onset dementia who described the questioning of his sexuality as insensitive and intrusive, and the fear of encountering homonegativity using services when being "outed" by his treating physician in his notes (Ward, 2000). The report includes also the case of a gay man who struggled to obtain recognition of his relationship by healthcare professionals when accessing services for his partner with dementia; he also experienced difficulties to be formally involved in the care process (Ward, 2000). A telephone support group for rural lesbian and gay caregivers of their partners with dementia was developed in northwestern North Carolina (Moore, 2002). A six-session format was used to provide information, reduce feelings of isolation, increase support with others, and enhance coping in everyday care activities of lesbian and gay family caregivers who had been taking care of their partners with dementia for an average of four years. Participants described previous experiences of insensitivity either as individuals or family caregivers; they had to face negative comments, pejorative remarks, and prejudice. The main topics of concern were the need to plan financial and legal issues, the need of social support when their partner becomes ill, and the need for services to support those facing the death of their partner (e.g., emotional support and funeral rituals targeting lesbian and gay elders).

A study aiming to explore the experiences of 20 gay and lesbian family caregivers of individuals with dementia in the UK showed that being part of a heterosexual group of family caregivers of individuals with dementia prevented her from addressing the main issues that are important for a lesbian woman caring for her mother, such as future adoption or the role of her partner in the caregiving process (Price, 2008). The recognition of their status as a minority within a minority leads LGBTQIA+ caregivers to experience stress when facing potentially unsafe healthcare environments, which causes isolation and unmet needs. In a follow-up qualitative study with 21 gay men and lesbian women who care, or cared, for a person with dementia, "coming out to service providers" emerged as the main theme (Price, 2010).

"Coming out" or the fact of proclaiming one's sexual orientation or gender identity to oneself and, subsequently to others can produce anxiety when it has to be done with multiple healthcare providers. The fear of encountering prejudice and negative attitudes towards LGBTQIA+ people can force some individuals to return to the closet by concealing their sexuality or "passing" as heterosexuals. However, sometimes family caregivers do not have the choice when they are "outed by dementia", that is, individuals with dementia will reveal their family caregivers' sexuality in the context of cognitive impairment. Another qualitative study reports the strategies that lesbian caregivers of an individual with dementia used to negotiate family issues in the context of their caregiving experience (Price, 2011). Universally, family caregivers of individuals with dementia are mainly women (Moreno et al., 2015). Surprisingly, the experience of lesbian family caregivers is seldom addressed and their contributions largely overlooked under the heterosexist lens. Lesbian women are involved in both their families of origin and families of choice (also known as social families that include ex-lovers and friends). When assuming the role of a family caregiver of an individual with dementia, lesbian family caregivers have to negotiate responsibilities with the biological family and they value the support of the families of choice in the caregiving role. In a follow-up study with the same sample, the author describes the hopes, fears, and plans for the future, as well as the way in which their own caregiving experiences have changed their views about their own health and social care needs (Price, 2012). Participants in the study were concerned about the recognition of their diverse sexualities in a positive and respectful way by healthcare professionals in case of illness. In this context, the potential for information leaks about their sexualities was perceived as stressful and anxiety provoking. The participants also valued the importance of maintaining links with other gay and lesbian people in case of illness. Regarding service provision, participants expressed their concern about damaging stereotypes that prevent the recognition of the individuals' needs.

Another qualitative study explored the experiences and needs of 30 LGBT Australians living with dementia and their partners (Barrett et al., 2015). 
Using in-depth interviews, they identified five key themes: a) impacts of dementia on sexual orientation and gender identity, with dementia changing the way that sexual orientation or gender identity is expressed (e.g., hiding sexual orientation or losing the right to express gender in residential care); b) conflict with families of origin making some LGBT seniors with dementia vulnerable to family members who do not value who they are; c) managing disclosure because LGBT seniors with dementia can lose control about their right to choose with whom they share information about their sexualities; d) intimate relationships and other safe spaces in terms of friendship networks and the difficulty to maintain them in the context of dementia; and e) the importance of inclusive services that prevent LGBT individuals with dementia to experience discrimination and delays in services as a result of homonegativity or transphobia.

Three studies addressed LGBTQIA+ concerns in HIV-related dementia (Boast \& Coid, 1994; Higgs \& Pinching, 2000; Meadows, Le Marechal, \& Catalan, 1999). A case report describes a gay man with an acute psychotic disorder in the context of an AIDSrelated complex (Boast \& Coid, 1994). Another case report presents a gay man who received compulsory treatment for HIV-related dementia when his partner contacted healthcare services to prevent him from flying abroad (Higgs \& Pinching, 2000). Both case reports address the ethical, legal, and personal boundaries that healthcare professionals may cross in their clinical practice when dealing with mental health issues in LGBTQIA+ people. Only one study examined the impact of HIV-associated dementia on a group of family caregivers of gay men diagnosed with this condition (Meadows et al., 1999). In addition to the stresses documented in family caregivers of individuals with non-HIV dementia, family caregivers of individuals with HIV-associated dementia provide terminal care sooner and reported lack of time for themselves, problems to access services (e.g., information and support), safety issues, relationship difficulties, behavioral problems (e.g., bizarre behavior, hallucinations, wandering, and disinhibition). There is a higher proportion of same-sex caregiver-care recipient dyads in the context of HIVassociated dementia, with family caregivers being more likely to be a parent or partner.

\section{Spinal cord injury}

Four references (7.8\%) were retained for LGBTQIA+ concerns following spinal cord injury
(SCI) after the screening of titles and abstracts (Burch, 2005, 2008; Miller, 2004; Williams, 2012). Miller (2004) reports that healthcare practitioners emphasize disability issues related to the SCI, but they fail to acknowledge their sexual orientation or leave their sexual needs completely unexplored. Unawareness of sexual orientation or gender identity represents an additional challenge to persons with SCI living authentically in having a "fear of profound rejection and even violence from loved ones when their sexuality is disclosed" (Miller, 2004) (p. 127).

In a study to evaluate healthcare providers' knowledge, attitudes, and self-efficacy to work with individuals with SCI with different sexual orientations, 402 SCI rehabilitation specialists responded to a survey regarding knowledge specific to their comfort level and recognition of sexual identities other than heterosexual (Burch, 2005, 2008). Indeed, $79 \%$ of the participants reported that they had never considered that individuals with SCI could be LGBT. The needs of LGBTQIA+ people with SCI could go unrecognized considering that individuals with SCI believe that sexual activity is a high quality of life priority and that providers felt $0-20 \%$ confidence levels for providing care to sexual minorities. This lack of acknowledgement limits rehabilitative education and may contribute to decreased LGBTQIA+ people with SCI returning to their healthcare providers. In addition, individuals with SCI identified as male historically received education regarding sexual performance while persons identified as female received education regarding reproduction (Burch 2005, 2007). Such rehabilitative education is heterosexist and confines sexual recovery to the ideology that males' sexual function focuses on vaginal intercourse for the male's physical pleasure, while a female's sexual function is for breeding/reproduction. The ideology further centers on the theme of the female's sexual function being vaginal reception of the male organ and the male's sexual function focusing on penile insertion into the woman's vagina. The heterosexist view omits other opportunities for sexual pleasure, as well being cissexist in creating an assumption that men have a penis and women have a vagina. Not all transgender persons opt for genital reconstruction surgery (formerly referred to as sexual reassignment surgery), thus leaving rehabilitation professionals providing care to LGBTQIA+ people with SCI with outdated information regarding sexual interaction when a man has a vagina, a woman has a penis, or a person is born intersex or of ambiguous sex. 
Williams (2012) presents a case study to provide an example of the extent to which the validity of a transgender individual's complaints can be minimized and her SCI diagnosis almost missed. Following a series of clinical misjudgments secondary to psychiatric morbidity and a history of HIV in a 62-year-old unemployed African American male-to-female transgender, the staff almost missed a traumatic SCI (Williams, 2012). The client requested hospital transfer complaining of poor care from the nursing staff and when her traumatic SCI was documented, she had already missed a time sensitive for evidence-based administration of steroids. Worsening quadriplegia was overlooked and misinterpreted as a conversion disorder, malingering, or attention seeking, leaving healthcare professionals in a state of skepticism failing to provide treatment in a timely manner.

\section{Traumatic Brain Injury/stroke}

After the screening of titles and abstracts, a total of five references $(9.8 \%)$ were retained for LGBTQIA+ concerns following traumatic brain injury (TBI) (Banja \& Banes, 1993; DeHope, 2006; Mapou, 1990; Murphy, 2003; O’Dell \& Riggs, 2001) and three for stroke (5.9\%) (Cheasty, Condren, \& Cooney, 2002; Jawad, Sidebothams, Sequira, \& Jamil, 2009; Miracle \& Miracle, 2009).

As noted by O'Dell and Riggs (2001), there is a significant dearth of literature addressing TBI and sexual orientation from the perspective of either individuals with TBI or the professionals providing care for same. In the context of working with individuals with TBI, as with the other areas of neurodisability, it is important to clarify values of treating staff and orient them appropriately to LGBTQIA+ issues. The ethics of healthcare when addressing the needs of LGBTQIA+ people with TBI includes obtaining information about sexual orientation, the inclusion of significant others in treatment, and conflict resolution among significant others and relatives (DeHope, 2006; Murphy, 2003) as well as sex education counseling (Mapou, 1990). Following a TBI, challenges may emerge including significant other and family conflicts, particularly so when preinjury sexual orientation had not been previously disclosed to family, and/or the relationship was unknown, resulting in subsequent debate on who will approve or provide care for the injured person (Mapou, 1990; Murphy, 2003). There are obviously no easy answers to these types of ethical quandaries aside from trying to assure communication that respects confidentiality and autonomy (O'Dell \& Riggs, 2001).

There may also be clinicolegal issues that confront professionals in the context of providing counseling services to LGBTQIA+ people, as well as heterosexual individuals with TBI during rehabilitation care (e.g., the existence of laws that might be in contradiction to their sexual practices such as anal sex). Some have taken the position that from a disability perspective, laws against anal sex, so-called sodomy laws, are not "only social anachronisms, but also are expressions of moral attitudes that unwittingly assign the sexual needs of persons with disability to an inferior status relative to that enjoyed by able-bodied persons" (Banja \& Banes, 1993) (p. 118). Additionally, another matter that often becomes problematic from a clinical service provision standpoint is the lack of legal recognition of non-heterosexual couples which may impact LGBTQIA+ people with TBI and their significant others in multiple ways, not just financially for rehabilitation service approval, but also in terms of insurance benefits in general (O'Dell \& Riggs, 2001). The issues regarding management of LGBTQIA+ people with stroke parallel those of TBI management. As with TBI, but probably to a greater extent, there is a substantive lack of literature on LGBTQIA+ concerns in the stroke population. Somewhat disparate from TBI populations, the stroke population tends to be older but LGBTQIA+ concerns are quite parallel. Many of these persons have close partner relationships in later life and worry that health professionals will discriminate against them and not treat them or their sexual concerns respectfully or with dignity (Miracle \& Miracle, 2009). Additionally, in the context of treating individuals following cerebrovascular accidents who have persistent impairment, it is important to understand age-related changes in both physical (e.g., vision and hearing loss, arthritis, cognitive decline) and sexual functioning including hormonal changes and resultant alterations in sexual response (Miracle \& Miracle, 2009).

Given the high incidence of cerebrovascular accidents and the consequential functional limitations of same, clinicians need to be aware of how LGBTQIA+ issues intersect with the impairments seen in this individual population. There are two case studies of altered sexual orientation in stroke survivors, although this is a rarely reported phenomenon (Cheasty et al., 2002; Jawad et al., 2009). Stroke-related impairments may include cognitive, behavioral, language and sensorimotor deficits that 
may impact on the expression of a person's sexual identity regardless of what that may be.

\section{Discussion}

The current study presented a critical review of the literature about neurological disorders in people who identify as LGBTQIA+ and is the first of its kind addressing sexual diversity and gender identity in the context of neurodisability. Interestingly, dementia is the most common neurodisability documented in LGBTQIA+ people. With ageing and associated cognitive impairment, LGBTQIA+ people want to make sure that their lives and identities will be respected and celebrated. There is an increasing awareness of the importance of families of choice and partners who become family caregivers. They want to be recognized as allies in the care of their loved ones with dementia. As such, they wish that their roles as partners of care are validated, their particular needs met, and their relationships and rights respected. Heterosexist behaviors, whether accidental or purposeful, contribute to the restriction of LGBTQIA+ community, family of choice, or queer partners. Social support and family, be they family of origin or family of choice, contribute to a person's sense of self and identity. Community creates social support and fosters love, not just love specific to physical intimacy, but love that is specific to self-appreciation and values related to resiliency and transcendence, as noted in positive psychology theories. To illustrate the importance of specific social support, a study conducted in a national sample of 169 transgender Australians showed that transgender individuals having frequent contact with LGBT peers, having higher income, and identifying as heterosexual showed greater resilience (Bariola et al., 2015).

A common point across the neurodisability spectrum is the fear of discriminatory care. "Treating everyone the same" is not the right approach because it equates equality of opportunity with equality of outcome (Price, 2010). Absence of recognition of individual differences and needs results in discriminatory and oppressive services perpetuating inequality and discrimination. It is essential that healthcare professionals develop a relationship with their LGBTQIA+ clients and building this relationship can take years (Higgs \& Pinching, 2000). Common mistakes in practice include assuming universal heterosexuality or monogamy, presume that family caregivers' partners are blood relatives, suppose that LGBTQIA+ people can be more accommodating because of their lack of "family responsibilities", and equating "single", "divorced" or "widowed" to absence of a same-sex relationship or presumed heterosexuality. Besides, it is wrong to suppose that all healthcare professionals practice within a heteronormative framework or that they are all heterosexual. As with any person following acquired brain injury, treating issues such as post-injury depression, anxiety, and substance abuse are all potentially important components of holistic management. Similarly, issues addressing changes in sexual behavior/libido including hyposexuality, hypersexuality/disinhibition or other changes in the expression of sexuality deem attention. As relevant, impairments in cognition, behavior and language must be addressed and considered in the context of provision of counseling services germane to sexuality and sexual function including safe sex practices, sexual positioning (which may be different from heterosexual individuals), and intimacy more generally, among other areas of potential relevance (O'Dell \& Riggs, 2001; Sandel et al., 2013).

Regarding the rights to access comprehensive sexual education for LGBTQIA+ people with neurodisabilities, the concept of safe sex practices should not be limited to the use of condoms. If a person is not educated on what sexual activity is (in its many forms), they may not be able to consent or to deny consent. Heteronormative sexual education often omits pleasure seeking in sex acts and its primary focus is often related to the avoidance or desire for pregnancy and sexually transmitted infection (STI) awareness. Sexual education, including adaptive technologies for persons with physical limitations, benefits LGBTQIA+ people with neurodisabilities to develop a relationship with pleasure, consent, and awareness of their sexuality. Informed and competent dialogue from a knowledgeable provider can lessen the "risky behaviors" of persons seeking guidance and assistance. The lack of education regarding romance and intimacy, as ways of social intelligence may instill inappropriate perceptions in LGBTQIA+ people with neurodisabilities to not expect the experience of intimate interactions outside of physical contact. Romantic gestures, with an acceptance of gender variance, can allow for expression and interaction in intimate manners with those for whom they feel attraction. Adaptive approaches to physical closeness (e.g., cuddling, hand holding), as well as adaptive approaches to sex acts can facilitate the expression of sexuality of LGBTQIA+ people with 
neurodisabilities, as it does for heterosexual or gender conforming individuals with neurodisabilities. Sexuality must be explored before it is assumed that the discussion must focus on a cisgender heterosexual orientation. Educating and training providers to offer individualized treatment to all persons regardless of their sexual orientation or gender identity is both paramount and ethical. Provider personal biases have the potential to negatively impact the quality of healthcare as well as individual health and well-being (Lapinski et al., 2014). When vocation or housing is a goal of rehabilitation treatment, sexual orientation and gender identity is of consideration secondary to prejudice and discrimination. Ramifications and implications for subacute and residential care, specific to severity of injury, personal care assistance, and independence needs require further dialogue to assure that the LGBTQIA+ individual with neurodisability has the optimal conditions for neurorehabilitation.

From the research perspective, studies of neurodisability in LGBTQIA+ people are mostly descriptive, cross-sectional, qualitative and case reports, conducted with small samples. Recruiting LGBTQIA+ people is difficult because they are "seldom-heard" and "hard-to-reach" populations given that they lack voice in care provision, they are in a system that does not fully meet their needs (Willis et al., 2011) and for fear of discriminatory care (Sabin, Riskind, \& Nosek, 2015). In the United States, 22 of 50 states protect persons identifying within the LGBTQIA+ community. Of the 22 , three states do not protect gender identity. This means that 28 of 50 states do not protect LGBTQIA+ people's basic rights (e.g., rights against termination or eviction) (ACLU, 2017). Methodologically, the aforementioned social issues affecting the LGBTQIA+ community provide a feasible explanation for the fact that most studies are conducted with LGB people, a few with trans people and there is a wide underrepresentation of individuals self-identified as queer, intersex, and other forms of sexual orientations and gender expressions. Another methodological reason for underrepresentation is the fact that only recently, researchers have started to record sexual orientation and gender identity in their studies. Even if some studies start to report sexual orientation and gender identity in the demographic characteristics of their samples, they are not included as variables in the analysis. For instance, a study from the United Kingdom noted that of 373 men with epilepsy, $88 \%$ reported being heterosexual, $4 \%$ gay, $2 \%$ bisexual and $6 \%$ preferred not to respond. Unfortunately, no further subanalysis of non-heterosexual participants was made (Sare, Rawnsley, Stoneman, \& Duncan, 2007).

Proposed research directions for the LGBTQIA+ community include (Rosendale \& Andrew Josephson, 2015): a) opportunity of access to primary care for LGBTQIA+ people, b) investigate rates of stroke and stroke outcomes in LGBTQIA+ people, c) compare rates of dementia with non-LGBTQIA+ samples, d) prevalence and outcomes of migraine and stroke in transgender people taking exogenous estrogen, e) response to anticonvulsant treatment in transgender women taking exogenous estrogen, f) incidence of thyroid-related neurological disorders in the transgender community, g) incidence of non-epileptic seizures in LGBTQIA+ people, and h) LGBTQIA+ participation in groups to support individuals with neurological conditions and their family caregivers. More specific research directions for LGBTQIA+ people with ID include (McCann et al., 2016): a) evaluation and impact of the profile of people with ID within government policy; b) epidemiological, transcultural, and multicenter studies; c) the evaluation of interventions about sexual health, psychological support, education and training programs; d) studies on the needs of lesbian and transgender people with ID. Studies about the health of LGBTQIA+ people are not capturing TBIs, probably because of the low report rates of hate crimes and homophobic violence to the police across the globe (75 to $90 \%$ mostly unreported), including crimes involving bodily harm (56\%) (Stotzer, 2014). Thus, research on LGBTQIA+ issues must include screening for TBI history.

Competence development and continuing education are ongoing processes to help healthcare providers to improve the quality of the services they offer. For the healthcare provider working with individuals with neurodisabilities, there are some reference books in LGBTQIA+ concerns regarding the health of sexual minorities (Meyer \& Northridge, 2007), LGBT elders (Harley \& Teaster, 2016; Ward, Rivers, \& Sutherland, 2012), a casebook of LGBT people with a section that is clinically oriented (Levounis, Drescher, \& Barber, 2012), cancer in the context of LGBT communities (Boehmer \& Elk, 2015), a casebook for counseling LGBT people and their families (Dworkin \& Pope, 2012), a book for those interested in alternative LGBT-parent families (Goldberg \& Allen, 2013), and an article with guidelines to provide an optimal mental health evaluation for an older LGBT adult (Yarns et al., 2016). Also, we provide an appendix that includes a list of resources 
to help clinicians to increase their knowledge and improve their LGBTQIA+ cultural competency.

A few limitations should be acknowledged. Even if we tried to widen our terms to capture all the literature available on LGBTQIA+ and neurodisability, it is possible that our keywords did not include alternative or local terms used to account for diverse forms of gender expression and non-heterosexualities (Moreno \& das Nair, 2016) failing to capture important pieces of information. However, the search was comprehensive to obtain a manageable number of references and provided useful information to be integrated in clinical practice, research and policies. In addition, the exclusion of literature published in languages other than English may have also left aside important sources. Grey literature was not captured and it is possible that some studies with LGBTQIA+ people with neurodisabilities were not published in mainstream journals.

In conclusion, being part of a positive change in the rehabilitation of LGBTQIA+ people with neurodisabilities is part of our obligation as healthcare providers who are self-reflective, critical, and willing to improve the quality of the services provided in an ethical framework. As clearly stated by the Yogyakarta principles: "everyone is entitled to enjoy all human rights without discrimination on the basis of sexual orientation or gender identity" (International panel of experts, 2007) (p. 10).

\section{Conclusions and recommendations for clinical practice, research and policy}

- Sexual orientation and gender identity are not preferences or part of a lifestyle. Healthcare providers must be aware of the fact that sexual orientation and gender identity are part of the individual's characteristics and avoid using terms as "preference", "lifestyle", or "personal choice" in the communication with their clients. Currently, there is no scientifically validated or ethically acceptable way to change sexual orientation or gender identity (Bailey et al., 2016) and there is a consensus of different psychological organizations around the harmful effects of those attempts (IPsyNet, 2017). As such, neurorehabilitation should include sexual orientation and gender identity as an important characteristic to provide optimal holistic care, to promote quality of life, and to facilitate sexual rehabilitation in the context of neurodisability.
- Use open-ended questions to explore the way in which a disability or illness affects sexuality and ask whether this is something the LGBTQIA+ client would like to discuss (e.g., what concerns you about your sexuality?) (Miracle \& Miracle, 2009).

- Explore with your LGBTQIA+ client whether they wish to disclose their sexual orientation or gender identity to others and explore the potential outcomes of the coming out process (e.g., potential job loss, discrimination from employers and co-workers, rejection from family and peers) (Miller, 2004).

- To advance the therapeutic alliance between the healthcare professional and the LGBTQIA+ client and to improve health outcomes, use gender-neutral non-heteronormative language that will communicate acceptance (Rosendale \& Andrew Josephson, 2015).

- As healthcare providers, challenge any homonegative and transphobic stereotypes that professionals may hold. Healthcare professionals are at different stages in their LGBTQIA+ cultural competency and increasing awareness on sexual diversity concerns is part of our professional and ethical responsibilities.

- Healthcare providers need to reflect about the way in which their own values and personal perspectives may impact their work with LGBTQIA+ people and find avenues to challenge their misconceptions and prejudicial attitudes.

- When there is a partner or significant other, promote inclusiveness by allowing them to be part of the care planning process of the LGBTQIA+ person having a neurodisability and allow them to share the same room when they need medical assistance in a healthcare facility.

- Often, biological families are not the main support group of LGBTQIA+ people. Families of choice or social families are significant support networks for LGBTQIA+ people with neurodisabilities. Sometimes, both biological families and social families have to negotiate their involvement in the care planning, but families of choice are not less important or valid in the decisions regarding care planning.

- It is important to provide emotional support to the family caregivers of LGBTQIA+ people living with neurodisabilities because the quality of informal care can determine the success of the treatment. Following the death of 
the LGBTQIA+ person living with a neurodisability, the family caregivers need emotional support from a nonjudgmental healthcare system to adjust and adapt to their new realities.

- Provide privacy in residential and nursing homes when the residents are visited by their partners or significant others. The need for a private space to freely express affection and closeness is important to maintain significant relationships and improve quality of life across the lifespan.

- When needed, offer the choice to LGBTQIA+ people to opt for intimate care provided by same-sex staff. Some LGBTQIA+ people may find intimate care more intrusive when provided by a person of different gender. When possible, let the individual or family caregiver make the choice according to the client's values and perspectives.

- In healthcare services and facilities, institutional materials, such as brochures and advertisement help to create a safe space for LGBTQIA+ people (e.g., social support groups, recreational activities, and reading materials targeting LGBTQIA+ people). Having these materials displayed in the waiting room can facilitate disclosure and communicate an atmosphere of acceptance and inclusion.

- Provide telephone and online support for LGBTQIA+ people with neurodisabilities and their family caregivers. Research demonstrates the utility and feasibility of these services to address the needs of LGBTQIA+ people.

- Modify the admission forms to reflect diverse realities (e.g., other significant relationships, alternative family configurations, preferred pronoun, sex and gender information). Using inclusive language in the admission documents may give time to LGBTQIA+ people to understand that they are in a safe space and decide in advance that they want to share their sexualities with their healthcare providers.

- In your healthcare facilities and websites, use signs to identify your service as LGBTQIA+friendly, such as the rainbow flag or any other symbol to advertise your awareness and acceptance of LGBTQIA+ people. Creating a virtual safe space can be a first step to invite LGBTQIA+ clients to your service.

- In your waiting rooms and rehabilitation facilities, use gender-neutral signs for single stall restrooms to lessen an individual's concern upon entering or exiting a restroom. Also, use single stall lockers and showers that allow private changing spaces.

- LGBTQIA+ cultural competent practice is an ongoing process and can be increased by providing specialized services for LGBT seniors living with dementia, increasing professional caregivers' competence and preparedness, and the creation of LGBT-affirmative environments, and continuing education on LGBTQIA+ concerns (Bauer, 2012).

- Education to reduce sexual prejudice among healthcare professionals and staff can include information on sexual orientation and LGBTQIA+ lives through videos, educational films, and scientific readings, direct contact with LGBTQIA+ people in an organized setting, or a combination of both contact and education (Bartos, Berger, \& Hegarty, 2014).

- When developing educational materials, make sure that the brochures, leaflets and websites use language that reflects inclusivity (e.g., "partner" or "significant other" instead of "husband or wife"; "parents" instead of "mother" and "father"; and "person" instead of "male" and "female"), as well as images that account for diversity by showing LGBTQIA+ care partnerships and alternative family configurations.

- Inclusive research must account for protocols that capture sexual orientation, gender identity, and other forms of non-heterosexual orientations or different forms of gender expression. There are templates describing the way to formulate the questions in research protocols with transgender individuals (Bauer, 2012). Sharing instruments that permit to gather comparable information is important to conduct studies with large sample sizes and effectively inform policy (Witten, 2014).

- Include gender diversity and sexual orientation explicitly in your rehabilitation center policies and ethical guidelines to make sure that your establishment aims to meet the needs of LGBTQIA+ people. It should include a way to denounce any discriminatory practice, a person responsible for addressing these situations, follow-up with the client and educational support for the staff. In all cases, confidentiality must be assured. 


\section{Conflict of interest}

None to report.

\section{References}

ACLU. (2017). Non-Discrimination Laws: State by State Information Map. Retrieved from (01-02-2017) https://www.aclu.org/ map/non-discrimination-laws-state-state-information-map

Anetzberger, G. J. (2004). Elder abuse: Case studies for clinical management. Clinical Gerontologist, 28(1/2), 43-53 11p.

Archibald, C. (2006). Gay and lesbian issues: Learning on the (research) job. Journal of Dementia Care, 14(4), 21-23 23p.

Bailey, J. M., Vasey, P. L., Diamond, L. M., Breedlove, S. M., Vilain, E., \& Epprecht, M. (2016). Sexual Orientation, Controversy, and Science. Psychol Sci Public Interest, 17(2), 45-101. doi: 10.1177/1529100616637616

Baird, A. D., Wilson, S. J., Bladin, P. F., Saling, M. M., \& Reutens, D. C. (2007). Neurological control of human sexual behaviour: Insights from lesion studies. J Neurol Neurosurg Psychiatry, 78(10), 1042-1049. doi: 10.1136/jnnp.2006.107193

Banja, J. D., \& Banes, L. (1993). Moral sensitivity, sodomy laws, and traumatic brain injury rehabilitation. Journal of Head Trauma Rehabilitation, 8(1), 116-119 114p.

Banks, M.E. (2003). Women with visible and invisible disabilities: Multiple intersections, multiple issues, multiple therapies - Part I - Preface. Women \& Therapy, 26(1-2), XXIII-XLI.

Bariola, E., Lyons, A., Leonard, W., Pitts, M., Badcock, P., \& Couch, M. (2015). Demographic and Psychosocial Factors Associated With Psychological Distress and Resilience Among Transgender Individuals. Am J Public Health, 105(10), 21082116. doi: 10.2105/AJPH.2015.302763

Barrett, C., Crameri, P., Lambourne, S., Latham, J. R., \& Whyte, C. (2015). Understanding the experiences and needs of lesbian, gay, bisexual and trans Australians living with dementia, and their partners. Australasian Journal on Ageing, 34, 34-38. doi: 10.1111/ajag.12271

Barrett, M. (1990). Resources on sexuality and physical disability (Perspectives on disability (p. 328-333). Palo Alto, CA: Health Markets Research; US.

Bartos, S. E., Berger, I., \& Hegarty, P. (2014). Interventions to reduce sexual prejudice: A study-space analysis and meta-analytic review. J Sex Res, 51(4), 363-382. doi: 10.1080/00224499.2013.871625

Bashe, P. R. (2012). Yet life keeps coming. Narrat Inq Bioeth, 2(3), 183-187. doi: 10.1353/nib.2012.0055

Bauer, G. (2012). Making sure everyone counts: Considerations for inclusion, identification and analysis of transgender and transsexual participants in health surveys (What a difference sex and gender make: A gender, sex and health research casebook (p. 59-67). Vancouver: CIHR Institute of Gender and Health.

Bel Bruno, R. (2009). Do we need to go there again? Newsweek, 153(19/20), 16-16 11p.

Boast, N., \& Coid, J. (1994). Homosexual erotomania and HIV infection. British Journal of Psychiatry, 164(6), 842-846.

Boehmer, U., \& Elk, R. (2015). Cancer and the LGBT community: Unique perspectives from risk to survivorship. Switzerland: Springer.

Burch, A. (2005). Health care providers' knowledge, attitudes, and self-efficacy for working with spinal cord injured patients with diverse sexual orientations. (Columbia University Teachers College). Retrieved from http://search.ebscohost.com/login. aspx ?direct=true \&db=rzh\&AN=109846387\&site=ehost-live

Burch, A. (2008). Health care providers' knowledge, attitudes, and self-efficacy for working with patients with spinal cord injury who have diverse sexual orientations. Physical Therapy, 88(2), 191-198 198p. doi: 10.2522/ptj.20060188

Casteel, C., Martin, S. L., Smith, J. B., Gurka, K. K., \& Kupper, L. L. (2008). National study of physical and sexual assault among women with disabilities. Inj Prev, 14(2), 87-90. doi: 10.1136/ip.2007.016451

Cheasty, M., Condren, R., \& Cooney, C. (2002). Altered sexual preference and behaviour in a man with vascular ischaemic lesions in the temporal lobe. International Journal of Geriatric Psychiatry, 17(1), 87-88.

Clinical digest. (2005). Nursing Standard, 19(42), 18-19 12p.

Colin, O. (2015). Acceptance of lesbian, gay, bisexual, and transgender people. JAMA Neurology, 72(10), 1209. doi: http://dx.doi.org/10.1001/jamaneurol.2015.2128

DeHope, E. (2006). The Case of Joan and Terri: Implications of Society's Treatment of Sexual Orientation for Lesbians and Gays with Disabilities (Case studies on sexual orientation \& gender expression in social work practice) (p. 44-46). New York, NY: Columbia University Press, US.

Dorsen, C., \& Van Devanter, N. (2016). Open arms, conflicted hearts: Nurse-practitioner's attitudes towards working with lesbian, gay and bisexual patients. J Clin Nurs, 25(23-24), 3716-3727. doi: 10.1111/jocn. 13464

Dworkin, S., \& Pope, M. (2012). Casebook for counseling lesbian, gay, bisexual, and transgender persons and their families. Retrieved from http://proxy.bibliotheques.uqam.ca/ login?url=http://onlinelibrary.wiley.com/book/10.1002/97811 19221715 Available at Wiley Online Library.

El-Ghoroury, N. H. (2012). Resilience and the narratives of parents of adults with autism spectrum disorders. Narrat Inq Bioeth, 2(3), 189-197. doi: 10.1353/nib.2012.0056

Esmail, S., Darry, K., Walter, A., \& Knupp, H. (2010). Attitudes and perceptions towards disability and sexuality. Disabil Rehabil, 32(14), 1148-1155. doi: 10.3109/09638280903419277

Farace, D. J., \& Schöpfel, J. (2010). Grey literature in library and information studies. Berlin, New York: De Gruyter Saur.

Glidden, D., Bouman, W. P., Jones, B. A., \& Arcelus, J. (2016). Gender Dysphoria and Autism Spectrum Disorder: A Systematic Review of the Literature. Sex Med Rev, 4(1), 3-14. doi: 10.1016/j.sxmr.2015.10.003

Goldberg, A. E., \& Allen, K. R. (2013). LGBT-Parent Families : Innovations in Research and Implications for Practice. New York, NY: Springer.

Harley, D. A., \& Teaster, P. B. (2016). Handbook of LGBT Elders An Interdisciplinary Approach to Principles, Practices, and Policies (First edition). doi: 10.1007/978-3-319-03623-6

Higgins, J., \& Green, S. (2011). Cochrane handbook for systematic reviews of interventions Version 5.1.0 [updated March 2011]: The Cochrane Collaboration.

Higgs, R., \& Pinching, A. J. (2000). Frontiers in care: A case of compulsory treatment in AIDS dementia. Case study and commentaries. Journal of Medical Ethics, 26(1), 61-65. doi: 10.1136/jme.26.1.61

Hunter, R. (1967). Transvestism, impotence and temporal lobe dysfunction. Journal of the Neurological Sciences, 4(2), 357-360. In brief. (2016). Nursing Standard, 30(36), 11-11 12/13p. 
Ingudomnukul, E., Baron-Cohen, S., Wheelwright, S., \& Knickmeyer, R. (2007). Elevated rates of testosteronerelated disorders in women with autism spectrum conditions. Hormones and Behavior, 51(5), 597-604. doi: 10.1016/j.yhbeh.2007.02.001

International panel of experts. (2007). The Yogyakarta principles: The Principles on the application of international human rights law in relation to sexual orientation and gender identity.

IPsyNet. (2017). International Psychology Network for Lesbian, Gay, Bisexual, Transgender and Intersex Issues: Guidelines and Practice Position Statements. Retrieved from (08-02-2017) http://www.apa.org/ipsynet/advocacy/policy/index.aspx

Jacobs, L. A., Rachlin, K., Erickson-Schroth, L., \& Janssen, A. (2014). Gender Dysphoria and Co-Occurring Autism Spectrum Disorders: Review, Case Examples, and Treatment Considerations. LGBT Health, 1(4), 277-282. doi: 10.1089/ lgbt.2013.0045

Jawad, S., Sidebothams, C., Sequira, R., \& Jamil, N. (2009). Altered sexual orientation following dominant hemisphere infarct. Journal of Neuropsychiatry and Clinical Neurosciences, 21(3), 353-354. doi: 10.1176/appi. neuropsych.21.3.353

Knocker, S. (2006). 'We don't have any gay people here'. Journal of Dementia Care, 14(4), 22-23 22p.

Lapinski, J., Sexton, P., \& Baker, L. (2014). Acceptance of lesbian, gay, bisexual, and transgender patients, attitudes about their treatment, and related medical knowledge among osteopathic medical students. J Am Osteopath Assoc, 114(10), 788-796. doi: 10.7556/jaoa.2014.153

Levounis, P., Drescher, J., \& Barber, M. E. (2012). The LGBT casebook. (First edition). Washington, DC: American Psychiatric Publishing.

Mapou, R. L. (1990). Traumatic brain injury rehabilitation with gay and lesbian individuals. Journal of Head Trauma Rehabilitation, 5(2), 67-72 66p.

Marshall, Z. (2012). Navigating risks and professional roles: Research with lesbian, gay, bisexual, trans, and queer young people with intellectual disabilities. J Empir Res Hum Res Ethics, 7(4), 20-33. doi: 10.1525/jer.2012.7.4.20

Mayer, K. H., Bradford, J. B., Makadon, H. J., Stall, R., Goldhammer, H., \& Landers, S. (2008). Sexual and gender minority health: What we know and what needs to be done. Am J Public Health, 98(6), 989-995. doi: 10.2105/AJPH.2007. 127811

McCann, E., Lee, R., \& Brown, M. (2016). The experiences and support needs of people with intellectual disabilities who identify as LGBT: A review of the literature. Res Dev Disabil, 57, 39-53. doi: 10.1016/j.ridd.2016.06.013

McClelland, A., Flicker, S., Nepveux, D., Nixon, S., Vo, T., Wilson, C., ...\& Proudfoot, D. (2012). Seeking safer sexual spaces: Queer and trans young people labeled with intellectual disabilities and the paradoxical risks of restriction. J Homosex, 59(6), 808-819. doi: 10.1080/00918369.2012.694760

McGovern, J. (2014). The forgotten: Dementia and the aging LGBT community. Journal of Gerontological Social Work, 57(8), 845-857. doi: http://dx.doi.org/10.1080/01634372. 2014.900161

Meadows, J., Le Marechal, K., \& Catalan, J. (1999). The burden of care: The impact of HIV-associated dementia on caregivers. AIDS Patient Care \& STDs, 13(1), 47-56 10p.

Meyer, I. H. (2014). Minority stress and positive psychology: Convergences and divergences to understanding LGBT health.
Psychology of Sexual Orientation and Gender Diversity, 1(4), 348-349. doi: $10.1037 / \mathrm{sgd} 0000070$

Meyer, I. H., \& Northridge, M. E. (2007). The health of sexual minorities: Public health perspectives on lesbian, gay, bisexual and transgender population. New York, NY: Springer.

Miller, E. (2004). Gay, lesbian, and bisexual individuals with SCI. SCI Psychosocial Process, 17(2), 126-128 123p.

Miracle, A. W., \& Miracle, T. S. (2009). Chapter 16: Sexuality in late adulthood. In B. R. Bonder, V. Dal Bello-Haas \& M. B. Wagner (dir.), (Vol. 3rd, p. 409-426 418p). Philadelphia, Pennsylvania: F.A. Davis Company/Publishers.

Moon, Y., \& Park, S. H. (2014). EndNote X7 for medical writing. Journal of the Korean Fracture Society, 27(3), 237.

Moore, W. R. (2002). Lesbian and gay elders: Connecting care providers through a telephone support group. Journal of Gay \& Lesbian Social Services: Issues in Practice, Policy \& Research, 14(3), 23-41. doi: http://dx.doi.org/10.1300/J041v14n03_02

Moorley, C., Neville, S., \& Johnson, J. (2016). Editorial: Being responsive: Promoting LGBTI health and wellbeing. J Clin Nurs, 25(23-24), 3413-3414. doi: 10.1111/ jocn. 13596

Moreno, A., \& das Nair, R. (2016). Towards a global LGBTI Psychology: International perspectives. Guest Editorial - Special Section on Lesbian, Gay, Bisexual, Transgender and Intersex (LGBTI) Psychology: International perspectives (volume 2). Psychology of Sexualities Review, 7(1), 11-14.

Moreno, J. A., Nicholls, E., Ojeda, N., De los Reyes-Aragon, C. J., Rivera, D., \& Arango-Lasprilla, J. C. (2015). Caregiving in Dementia and its Impact on Psychological Functioning and Health-Related Quality of Life: Findings from a Colombian Sample. J Cross Cult Gerontol, 30(4), 393-408. doi: 10.1007/s10823-015-9270-0

Moriarty, J. (2003). Gay and Lesbian Carers Network. Dementia (14713012), 2(1), 133-134 132p.

Morris, C., Janssens, A., Tomlinson, R., Williams, J., \& Logan, S. (2013). Towards a definition of neurodisability: A Delphi survey. Dev Med Child Neurol, 55(12), 1103-1108. doi: $10.1111 / \mathrm{dmcn} .12218$

Munson, S., \& Cook, C. (2016). Lesbian and bisexual women's sexual healthcare experiences. J Clin Nurs, 25(23-24), 3497-3510. doi: 10.1111/jocn.13364

Murphy, T. F. (2003). Bioethics as if relationships matter. Hastings Center Report, 33(5), 15-16.

Newman, R. (2005). Being equally different: Lesbian and gay carers. Psychiatric Bulletin, 29(7), 266-267. doi: http://dx.doi.org/10.1192/pb.29.7.266

Newsom, C. R., Weitlauf, A. S., Taylor, C. M., \& Warren, Z. E. (2012). Parenting adults with ASD: Lessons for researchers and clinicians. Narrat Inq Bioeth, 2(3), 199-205. doi: 10.1353/nib.2012.0057

Nosek, M. A., Howland, C. A., Rintala, D. H., Young, M. E., \& Chanpong, G. F. (2001). National study of women with physical disabilities: Final report. Sexuality and Disability, 19(1), 5-39.

O’Dell, M. W., \& Riggs, R. V. (2001). Traumatic brain injury in gay and lesbian persons: Practical and theoretical considerations. Brain Injury Source, 5(3), 22-42 23p.

Parkinson, J. (2015). Gender dysphoria "cured" by status epilepticus. Australas Psychiatry, 23(2), 166-168. doi: $10.1177 / 1039856214568223$

Parsi, K., \& Elster, N. (2012). Growing up with autism: Challenges and opportunities of parenting young adult children with 
autism spectrum disorders. Narrat Inq Bioeth, 2(3), 207-211. doi: 10.1353/nib.2012.0058

Price, E. (2003). Dementia and the gay community. Journal of Dementia Care, 11(5), 38.

Price, E. (2008). Pride or prejudice? Gay men, lesbians and dementia. British Journal of Social Work, 38(7), 1337-1352 1316p.

Price, E. (2010). Coming out to care: Gay and lesbian carers' experiences of dementia services. Health \& Social Care in the Community, 18(2), 160-168 169p. doi: 10.1111/j.13652524.2009.00884.x

Price, E. (2011). Caring for mum and dad: Lesbian women negotiating family and navigating care. British Journal of Social Work, 41(7), 1288-1303 1216p. doi: bjsw/bcr015

Price, E. (2012). Gay and lesbian carers: Ageing in the shadow of dementia. Ageing and Society, 32(3), 516-532. doi: 10.1017/S0144686X11000560

Rosendale, N., \& Andrew Josephson, S. (2015). The Importance of lesbian, gay, bisexual, and transgender health in neurology what's in a name? JAMA Neurology, 72(8), 855-856.

Sabin, J. A., Riskind, R. G., \& Nosek, B. A. (2015). Health care providers' implicit and explicit attitudes toward lesbian women and gay men. Am J Public Health, 105(9), 1831-1841. doi: 10.2105/AJPH.2015.302631

Sandel, M. E., Delmonico, R., \& Kotch, M. J. (2013). Sexuality and intimacy following traumatic brain injury. In N. Zasler \& R. Zafonte (dir.), Brain injury medicine: Principles and practice (p. 954-973). New York: Demos Publishers.

Sare, G., Rawnsley, M., Stoneman, A., \& Duncan, S. (2007). Men with epilepsy-The lost tribe?. Results of a nationwide survey of men with epilepsy living in the UK. Seizure, 16(5), 384-396. doi: 10.1016/j.seizure.2007.02.007

Saxe, A., \& Flanagan, T. (2013). Factors that impact support perceptions of the sexuality of adults with developmental disabilities: A quantitative analysis. Sexuality and Disability, 32(1), 45-63. doi: 10.1007/s11195-013-9314-8

Skagerberg, E., Di Ceglie, D., \& Carmichael, P. (2015). Brief report: Autistic features in children and adolescents with gender dysphoria. J Autism Dev Disord, 45(8), 2628-2632. doi: 10.1007/s 10803-015-2413-x

Stotzer, R. L. (2014). Bias crimes based on sexual orientation and gender identity: Global prevalence, impacts, and causes. In D. Peterson \& V. R. Panfil (dir.), Handbook of LGBT communities, crime, and justice (pp. 45-64). New York: Springer.

Strang, J. F., Meagher, H., Kenworthy, L., de Vries, A. L., Menvielle, E., Leibowitz, S., ...\& Anthony, L. G. (2016). Initial Clinical Guidelines for Co-Occurring Autism
Spectrum Disorder and Gender Dysphoria or Incongruence in Adolescents. J Clin Child Adolesc Psychol, 1-11. doi: 10.1080/15374416.2016.1228462

Tallentire, L., Smith, M., David, L., Roberts, A., Bruce, Morrow, S., .. \& \& Smith, I. (2016). Stories of people who have attended a lesbian, gay, bisexual and trans support group in a secure intellectual disability service. J Appl Res Intellect Disabil. doi: 10.1111/jar.12281

Thomas, P. R., \& DeAlwis, K. (1995). Transvestism in a person with learning disabilities presenting with behavioural problems. J Intellect Disabil Res, 39 (Pt 5), 454-456.

Umberson, D., Thomeer, M. B., Reczek, C., \& Donnelly, R. (2016). Physical illness in gay, lesbian, and heterosexual marriages: Gendered dyadic experiences. J Health Soc Behav, 57(4), $517-$ 531. doi: $10.1177 / 0022146516671570$

Van Der Miesen, A. I., Hurley, H., \& De Vries, A. L. (2016). Gender dysphoria and autism spectrum disorder: A narrative review. Int Rev Psychiatry, 28(1), 70-80. doi: 10.3109/09540261.2015.1111199

Ward, R. (2000). Waiting to be heard - dementia and the gay community. Journal of Dementia Care, 8(3), 24-25 22p.

Ward, R., Rivers, I., \& Sutherland, M. (2012). Lesbian, gay, bisexual and transgender ageing: Biographical approaches for inclusive care and support. London: Jessica Kingsley Publishers.

Ward, R., Vass, A. A., Aggarwal, N., Garfield, C., \& Cybyk, B. (2005). A kiss is still a kiss? The construction of sexuality in dementia care. Dementia (14713012), 4(1), 49-72 24p.

Williams, A. (2012). Transsexualism, personality disorders, and spinal cord injury. Journal of Gay \& Lesbian Mental Health, 16(1), 56-65. doi: http://dx.doi.org/10.1080/ 19359705.2011.613301

Willis, P., Ward, N., \& Fish, J. (2011). Searching for LGBT Carers: Mapping a Research Agenda in Social Work and Social Care. British Journal of Social Work, 41(7), 1304-1320. doi: 10.1093/bjsw/bcr114

Witten, T. M. (2014). It's not all darkness: Robustness, resilience, and successful transgender aging. LGBT Health, 1(1), 24-33. doi: 10.1089/lgbt.2013.0017

Yarns, B. C., Abrams, J. M., Meeks, T. W., \& Sewell, D. D. (2016). The mental health of older LGBT adults. Curr Psychiatry Rep, 18(6), 60. doi: 10.1007/s11920-016-0697-y

Zasler, N. D., \& Martelli, M. F. (2011). Sexual dysfunction. In J. M. Silver, W. B. McAllister \& S. C. Yudofsky (dir.), Textbook of traumatic brain injury (p. 397-414). Washington, DC: American Psychiatric Publishing. 


\section{Appendix. List of resources}

\section{LGBTQIA+ cultural competency}

- https://www.hhs.gov/programs/topic-sites/lgbt/ enhanced-resources/competency-training/ index.html (Health and human services cultural competency training).

- https://www.diverseandresilient.org/resources/ lgbt-competency-toolkit/ (LGBTQ Competency Toolkit)

- https://www.ama-assn.org/delivering-care/phy sician-resources-lgbtq-inclusive-practice (Physician resources for an LGBTQ-inclusive practice).

- http://www.glma.org/index.cfm?fuseaction= Page. viewPage\&pageId=1025\&grandparentID= 534\&parentID=940\&nodeID=1 (GLMA cultural competence webinar series for providers and researchers).

- http://www.jointcommission.org/assets/1/18/ LGBTFieldGuide.pdf (Advancing effective communication, cultural competence, and patient- and family-centered care for the Lesbian, Gay, Bisexual, and Transgender Community).

- http://www.cancer-network.org/downloads/best _practices.pdf (Best Practices in Creating and Delivering LGBTQ Cultural Competency Trainings for Health and Social Service Agencies)

\section{LGBTQIA+ aging and dementia}

- http://www.mhpf.org.uk/sites/default/files/docu ments/publications/29042016_dementia_care and_lgbt_communities_a_good_practice_paper. pdf (Dementia care and LGBT communities: a good practice paper).

- http://www.openingdoorslondon.org.uk/resour ces/The\%20Whole\%200f\%20Me.pdf (The whole of me...Meeting the needs of older lesbians, gay men and bisexuals living in care homes and extra care housing: A resource pack for professionals)

- https://www.alzheimers.org.uk/download/down loads/id/1788/moving_into_a_care_home_-_ advice_for_lesbian_gay_and_bisexual_people.pdf (Moving into a care home - advice for lesbian, gay and bisexual people).

- https://www.alzheimers.org.uk/download/down loads/id/1833/factsheet_supporting_lesbian_gay _and_bisexual_people_with_dementia.pdf (Sup- porting lesbian, gay and bisexual people with dementia).

- https://www.alz.org/national/documents/bro chure_lgbt_caregiver.pdf (LGBT caregiver concerns: important considerations for LGBT caregivers).

- http://forge-forward.org/aging/ (Transgender Aging Network) http://www.sageusa.org/ (SAGE-Services and Advocacy for GLBT Elders)

\section{LGBTQIA+ health}

- http://www.lgbthealtheducation.org (National LGBT health education center).

- http://www.apa.org/pi/lgbt/resources/lgbt-hea lth.aspx (American Psychological Association - Lesbian, Gay, Bisexual and Transgender health).

- http://howardbrown.org/wp/mission-and-over view/ (Howard Brown Health).

- http://fenwayhealth.org (Fenway Health).

- http://www.glma.org (Gay and Lesbian Medical Association - GLMA)

- https://nursing.unc.edu/files/2014/04/13128.pdf (The health of lesbian, gay, bisexual, and transgender people: building a foundation for better understanding).

- http://www.wpath.org/ (World Professional Association for Transgender Health - WPATH)

- http://www.lgbthealth.net/ (National Coalition for LGBT Health).

- http://ismh-isms.com (Institute for Sexual Minority Health offers LGBT).

- http://epath.eu (European Professional Association for Transgender Health - EPATH).

\section{Professional associations and practice position statements}

- http://www.apa.org/ipsynet/ (International Psychology Network for Lesbian, Gay, Bisexual, Transgender and Intersex Issues - American Psychological Association).

- http://www.apa.org/ipsynet/practice/guidelines/ index.aspx (Guidelines and Practice Position Statements - American Psychological Association).

\section{Smoking prevention for LGBTQIA+}

- https://thisfreelife.betobaccofree.hhs.gov (This Free Life).

- https://www.cdc.gov/tobacco/campaign/tips/ groups/lgbt.html (Tips for former smokers for 
Specific Groups - Lesbian, Gay, Bisexual, and Transgender).

\section{Dis(Different)Ability LGBTQIA+Resources}

- http://www.deafrad.org/ (Rainbow Alliance of the Deaf).

- http://www.deafqueer.org/ (Deaf Queer Resource Center).

\section{Miscellaneous}

- http://lgbt.newark.rutgers.edu/localnationalre sources (Rutgers, The State University of New Jersey).

- https://spectrumcenter.umich.edu/ (University of Michigan list of international resources for LGBTQ persons).

- www.pflag.org (Parents and Friends of Lesbians and Gays - PFLAG National Headquarters).

- http://www.isna.org/ (The Intersex Society of North America).

- http://www.hrc.org/youth\&num;.UMIbArJvHIg (Human Rights Campaign).

- http://www.lambdalegal.org/ (Lambda Legal).

- http://transequality.org/ (National Center for Transgender Equality).

- http://nbjc.org/ (National Black Justice Coalition).

- http://www.ilga.org/ (International lesbian, gay, bisexual, trans and intersex association).

- https://www.outrightinternational.org/ (OutRight Action International - Formerly known as International Gay and Lesbian Human Rights Commission).
- http://hrw.org/doc/?t=lgbt (Human Rights Watch).

- http://www.glaad.org/ (Gays \& Lesbians Alliance Against Defamation).

- http://www.amnestyusa.org/Our_Issues/LGBT_ Human_Rights/page.do?id=1011002\&n1=3\&n 2=36 (Amnesty International LGBT Resources).

- http://www.familleslgbt.org/training.php?lang =en (LGBT Family Coalition).

- http://www.caaws-homophobiainsport.ca/e/in dex.cfm (Homophobia in sport).

- http://globalphilanthropyproject.org (LGBTQ IA+ funding opportunities).

- https://oii.org.au/20042/on-requests-for-resea $\mathrm{rch} /$ (Organisation Intersex Australia Limited).

- http://www.stonewall.org.uk/get-involved/edu cation (Stonewall: acceptance without exception).

\section{Harassment}

- http://www.thetaskforce.org/downloads/repo rts/reports/TransgenderEquality.pdf (NGLTF Transgender Equality Booklet).

- http://www.dayofsilence.org/ (National Day of Silence).

- https://gsanetwork.org/resources/gsa-actionsevents/transgender-day-remembrance (Transgender Day of Remembrance).

- https://www.splcenter.org/issues/lgbt-rights (Southern Poverty Law Center). 